Classification

Physics Abstracts

52.20

\title{
Atomic oxygen recombination at the wall in a time afterglow
}

\author{
L. Magne, H. Coitout, G. Cernogora and G. Gousset \\ Laboratoire de Physique des Gaz et des Plasmas, Université Paris-Sud, Bât. 212, 91405 Orsay \\ Cedex, France
}

(Received 4 March 1993, revised 10 June 1993, accepted 28 June 1993)

\begin{abstract}
Résumé. - La densité d'oxygène atomique dans l'état fondamental est mesurée dans la postdécharge d'une décharge pulsée par spectroscopie d'absorption résonante dans l'ultraviolet lointain. L’évolution de la densité atomique pendant la post-décharge est la somme de deux décroissances exponentielles. La probabilité de réassociation des atomes à la paroi en pyrex du tube à décharge est déduite de la décroissance la plus rapide. La valeur ainsi obtenue est $\gamma=(2,4 \pm 1.1) \times 10^{-3}$. Des interprétations de la décroissance plus lente en terme de gain atomique sont évoquées dans la discussion.
\end{abstract}

\begin{abstract}
Atomic oxygen ground state density is measured in the time afterglow of a pulsed discharge with resonant absorption spectroscopy in the vacuum ultraviolet range. The evolution of atomic density during the afterglow is a sum of two exponential decays. The recombination probability at the pyrex wall of the discharge tube is deduced from the fastest decay. The so obtained value is $\gamma=(2.4 \pm 1.1) \times 10^{-3}$ Interpretations of the slowest decay as possible atomic gain are brought up in the discussion.
\end{abstract}

\section{Introduction.}

Atomic oxygen sources are of great interest for the study of materials behaviour under reactive atomic species exposure. For instance, fast oxygen atom beams are required in order to simulate atomic flux on surfaces, in the low Earth orbital conditions [1,2]. The problems of catalytic recombination, oxidation or erosion, during the atmospheric reentry can also be simulated using hypersonic flows of active species [3].

Surface treatments by plasma device are spreading out as industrial applications for high technology materials. The application field of low pressure oxygen discharges is now broadening to supraconductor realization [4]. Conductive properties of thin films strongly depend on the oxygen stoichiometry. Oxygen deficiency in $\mathrm{YBaCuO}$ samples can be corrected by oxidation caused by oxygen atoms carried by the flowing afterglow of a radio frequency discharge [5]. In order to improve wettability and adhesion properties, surface treatment of polymers can also be performed in the flowing afterglow of microwave discharge [6]. 
In order to optimize atomic oxygen sources, experimental studies of atoms production within discharges, as well as their transport in flowing afterglows, are essential. Thus, many diagnostics for atomic density measurements are now efficient. Atomic density in flowing afterglow can be measured by: calorimetry [7-9], $\mathrm{NO}$ [10] or $\mathrm{NO}_{2}$ [11-14] titration, $\mathrm{O}_{3}$ synthesis in a liquid nitrogen trap $[15,16]$, mass spectroscopy [17], silver-coated quartz monitor [18] or resonant absorption spectroscopy in the vacuum ultraviolet range (V.U.V.) $[5,19,20]$. Laser spectroscopy techniques also are of great use for obtaining in situ measurements with a good spatial resolution. The spatial distribution of atomic ground state density in an effusive beam from a D.C. discharge, has recently been established using resonant multiphoton ionization (R.M.P.I.) and two photon laser induced fluorescence (L.I.F.) [21]. Within discharges, atomic oxygen density measurements can be performed by L.I.F. [22], actinometry [21] and V.U.V. absorption spectroscopy [19, 21, 23].

Low pressure oxygen discharges are a complex medium where numerous species coexist, such as metastable molecules, ozone, positive and negative ions and atoms. The kinetics involving the heavy particles depend on the working conditions of the discharge and many models have been elaborated [24-31]. In spite of the difficulties of obtaining a forecasting model for the heavy particles densities, the main processes fixing the atomic density are known to be the dissociation by electronic collisions and the recombination at the wall [23]. So the value of the recombination probability at the wall $\gamma$ is an all-important data in order to predict the atomic density available within the sources as well as losses during transport in a flowing afterglow.

Numerous works are devoted to the determination of $\gamma$ for several materials. Concerning pyrex glass, which is one of the most commonly used materials for confining low temperature plasmas or flowing afterglows, the published values for $\gamma$ range from $2 \times 10^{-5}$ [32] to $5 \times 10^{-3}$ [28]. The higher values are obtained for pyrex under plasma exposure, from a kinetic model for a D.C. low pressure discharge under steady state conditions [28]. All experimental values are given for pyrex in flowing afterglows. These results are always smaller than the estimated ones under discharge conditions.

The aim of this work is to measure the evolution of atomic ground state density in a static time afterglow, using the resonant V.U.V. absorption spectroscopy technique, in order to determine an experimental value of the recombination probability at the wall, for pyrex under plasma exposure.

\section{Experimental set-up.}

The experimental set-up is shown in figure 1 .

Pure oxygen dissociation and excitation are obtained with a pulsed discharge in a $50 \mathrm{~cm}$ long and $1.5 \mathrm{~cm}$ inside diameter pyrex tube. The extremities of this tube are closed with $\mathrm{MgF}_{2}$ windows allowing V.U.V. radiations transmission.

In order to remove impurities, a weak gas flow, regulated with a mass flow controller, is maintained in the discharge tube. However, this flux is low enough to neglect the pressure gradient along the observation direction. Upstream, pressure is measured by a pirani gauge. Downstream, pumping efficiency is limited using a throttle valve and pressure is measured with an absolute capacitance gauge. These appliances allow us to adjust flowing conditions. Under these conditions, the gas residence time in the observation zone varies from $0.5 \mathrm{~s}$ to $3 \mathrm{~s}$.

The generator supplies high voltage pulses with adjustable duration, discharge current and repetition frequency. Previous measurements [33] have shown that for long pulses (5 ms) and high current $(300 \mathrm{~mA})$, the interpretation of results is not easy because of gas heating and also because of the creation of long life species, which can complicate atomic kinetics in the afterglow. In order to avoid these problems, the pulse width and the discharge current must be 


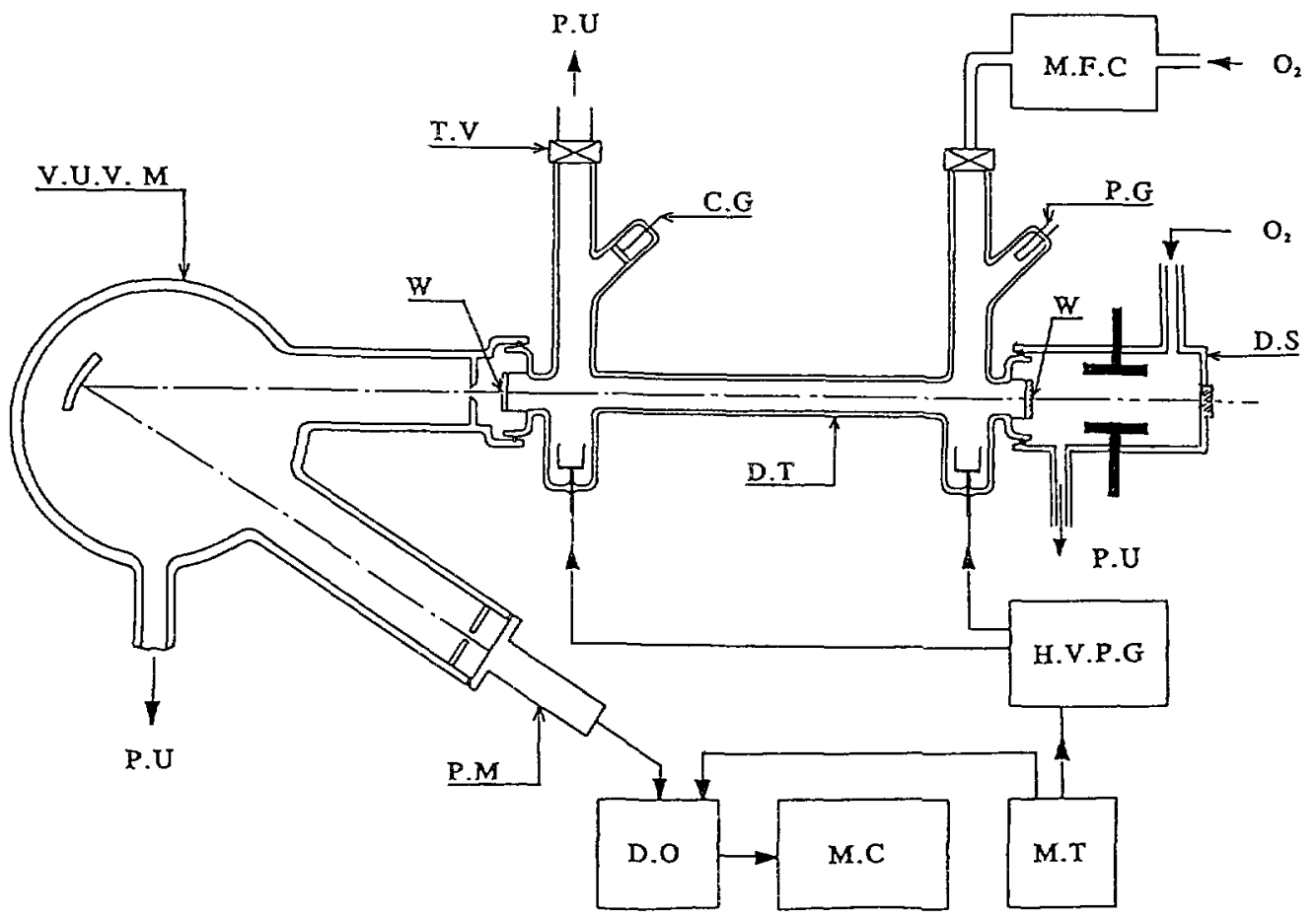

Fig. 1. - Experimental set-up. M.F.C. : Mass Flow Controller, P.G. : Pirani Gauge. C.G. : Capacitance Gauge, T.V.: Throttle Valve, P.U. : Pumping Unit, D.S. : Damany Source, D.T. : Discharge Tube, W : $\mathrm{MgF}_{2}$ Windows, V.U.V.M. : Vacuum Ultra Violet Monochromator, P.M. : Solar Blind Photomultiplier, M.T. : Master Trigger, H.V.P.G. : High Voltage Pulse Generator, D.O. : Digital Oscilloscope, M. C. : Microcomputer.

as low as possible. The value of pulse duration is $30 \mu \mathrm{s}$ for the major part of the results presented in this paper, and the current value ranges from $30 \mathrm{~mA}$ to $200 \mathrm{~mA}$. The characteristic decay time of the current is about $1 \mu \mathrm{s}$. Pulses repetition frequency must be slow enough to make sure that atomic density is returned to zero before the following pulse. This is the reason why we chose this frequency between 0.1 and $1 \mathrm{~Hz}$. Under these conditions, we can obtain discharges for pressures ranging from $2 \times 10^{-2}$ to 5 Torr.

The discharge tube is lighted at one side by V.U.V. radiations emitted by a low pressure Penning discharge (Damany Source). This V.U.V. source is constituted by a D.C. discharge in pure oxygen in which electrons are confined by a steady magnetic field. The three lines of the resonant atomic triplet $\mathrm{O}\left({ }^{3} \mathrm{~S}^{0}\right) \rightarrow \mathrm{O}\left({ }^{3} \mathrm{P}_{J}\right)+h \nu$, shown in figure 2 , are emitted with high intensity and good stability. The resonant absorption spectroscopy diagnostic requires the measurement of the incident lines shapes. The high resolution spectrum of this triplet, has been measured with a $10 \mathrm{~m}$ focal length spectrometer at the Observatoire de Meudon (France). The high resolution profiles of the three lines are reported in figure 3 for working conditions of the Damany source fixed to $P=4 \times 10^{-2}$ Torr and $I=200 \mathrm{~mA}$. In this figure we can see a strong self absorption of the $J=2$ component.

V.U.V. radiations, transmitted through the discharge tube, are analyzed in wavelength by a $50 \mathrm{~cm}$ focal length monochromator (ASM 50 Jobin Yvon). A solar blind photomultiplier (EMI 9413B) with a $\mathrm{MgF}_{2}$ window and a CsI photocathode detects the transmitted light for the selected wavelength. This detector is efficient for wavelengths ranging from $120 \mathrm{~nm}$ to 


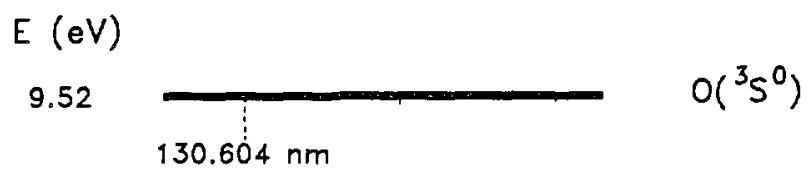

$130.487 \mathrm{~nm}$

\section{$130.217 \mathrm{~nm}$}

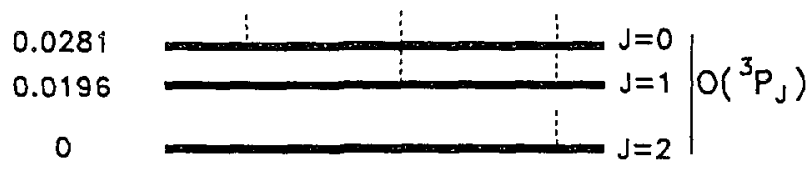

Fig. 2. - Resonant atomic triplet $\mathrm{O}\left({ }^{3} \mathrm{~S}^{0}\right) \rightarrow \mathrm{O}\left({ }^{3} \mathrm{P}_{1}\right)+h \nu$.

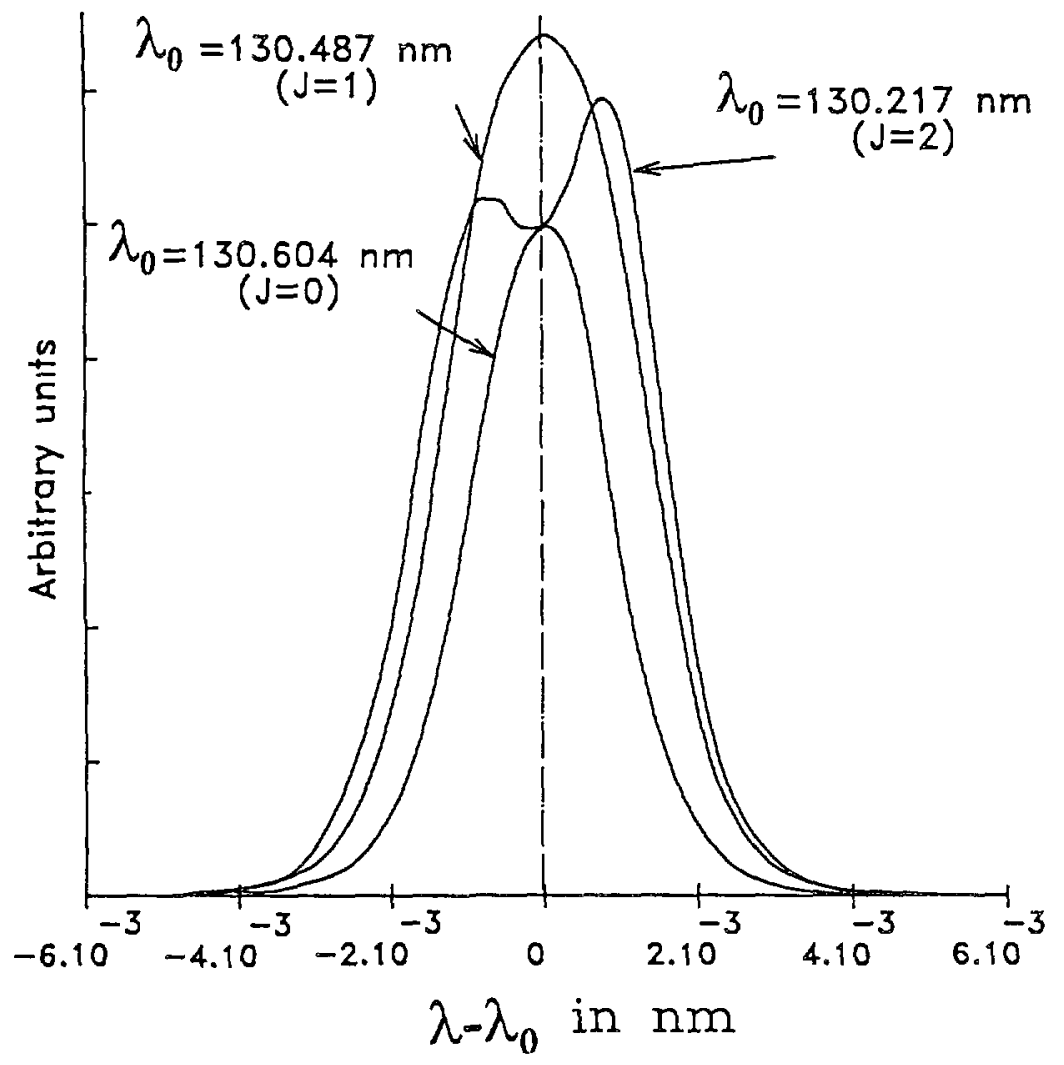

Fig. 3. - High resolution profiles of the three lines of the atomic triplet emitted by the Damany source for $P=4 \times 10^{-2}$ Torr and $I=200 \mathrm{~mA}$. 
$210 \mathrm{~nm}$. The cut off of this detector for high wavelengths allows us work with the second order of the grating without any overlapping between the atomic triplet and the first order. A spectrum of the atomic triplet emitted by the source, and obtained with our experimental device is presented in figure 4 . We can see that the lines are strongly broadened by the apparatus function of the monochromator. As a matter of fact, the widths of the emission lines plotted in figure 3 are $3.43 \times 10^{-3} \mathrm{~nm}, 2.81 \times 10^{-3} \mathrm{~nm}$ and $2.11 \times 10^{-3} \mathrm{~nm}$ for the component $J=2, J=1$ and $J=0$ respectively while the apparatus function has a width of $5.4 \times 10^{-2} \mathrm{~nm}$. In spite of that broadening, the three lines are well resolved. The weak overlapping will be taken into account in the diagnostic calibration.

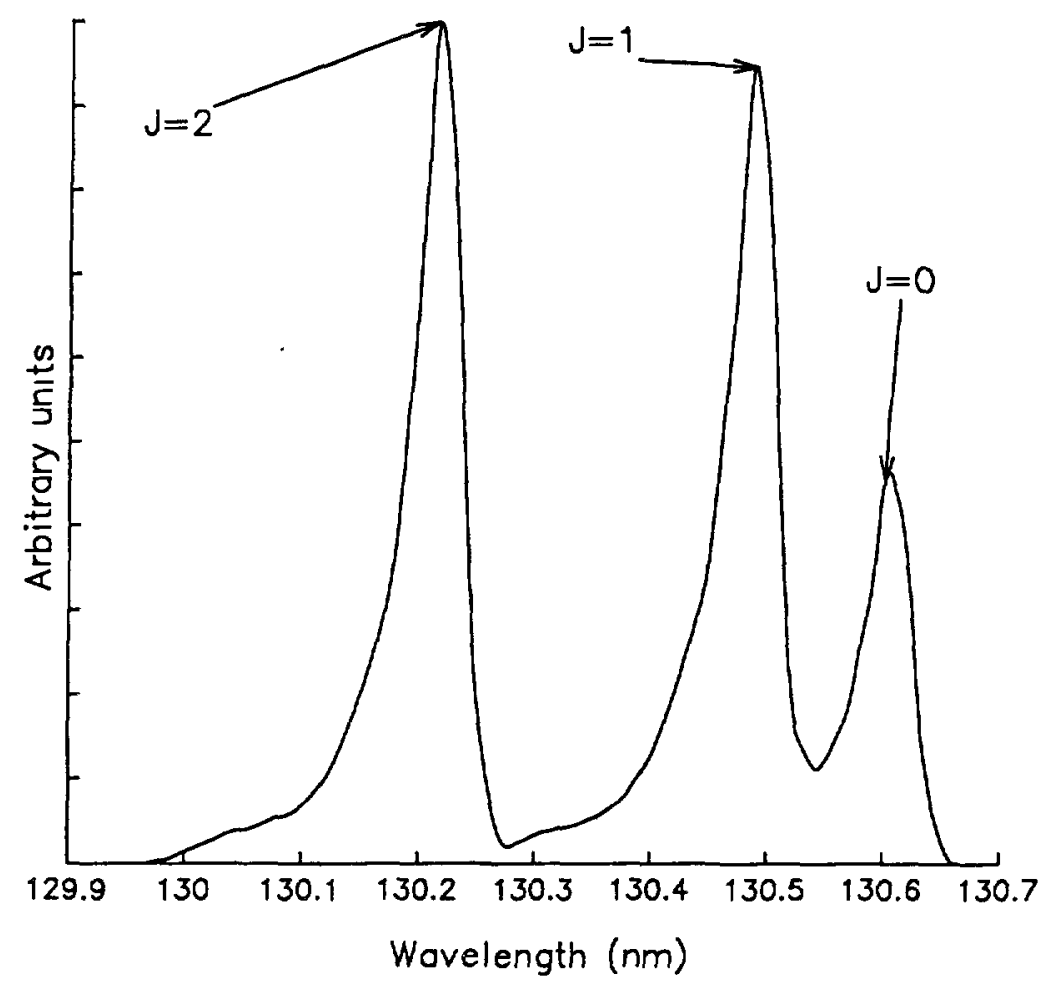

Fig. 4. - Spectrum of the atomic triplet emitted by the Damany source obtained with our experimental device for $P=4 \times 10^{-2}$ Torr and $I=200 \mathrm{~mA}$.

P.M. output signal is connected to a numeric oscilloscope (Le Croy 9400) in order to average and digitalize the transmitted signal. The recorded traces are transferred to a microcomputer.

The reproducibility of atomic density measurements in oxygen discharges, strongly depends on gas purity and on the surface state of the wall. This second point is due to the fact that recombination at the wall is the main loss process of atomic oxygen. Recombination probability is very sensitive to the surface state. In order to improve the cleanliness of the discharge and to keep the same surface state of the wall, before each experiment, a D.C. discharge with a high gas flux is maintained during about one hour before the pulsed mode. During this treatment, the discharge tube is heated by hot resistive wires. 


\section{Diagnostic calibration.}

A typical plot of the transmitted signal as a function of time, for the three lines, is reported in figure 5. We choose the instant $t=0$ at the beginning of the time afterglow. Before the pulse $(t<0)$, we detect the transmitted signal without atoms. This signal is time independent. The pulse itself is not visible in this plot because of the time scale. During the afterglow, the signal is time dependent. It increases up and it returns to the value without atoms, as the atomic density decreases until it returns to zero. From these measurements, we define the ratio of transmitted signal during the afterglow over the signal before the discharge:

$$
R_{\exp }(\lambda, t)=\frac{I_{\mathrm{T}}(\lambda, t)}{I_{\mathrm{T}}(\lambda, t<0)}
$$

where $\lambda$ is the central wavelength of the selected component.

Before the discharge occurs, the signal is constituted of the incident intensity emitted by the source which is absorbed by molecules in the ground state $\mathrm{O}_{2}\left(\mathrm{X}^{3} \Sigma\right)$. Taking into account the convolution with the device apparatus function, the transmitted signal is given by :

$$
I_{\mathrm{T}}(\lambda, t<0)=\int_{-\infty}^{+\infty} I_{0}(\lambda-y) F(y) \exp \left(-\sigma_{\mathrm{X}}(\lambda-y)\left[\mathrm{O}_{2}(\mathrm{X})\right](t<0) L\right) \mathrm{d} y .
$$

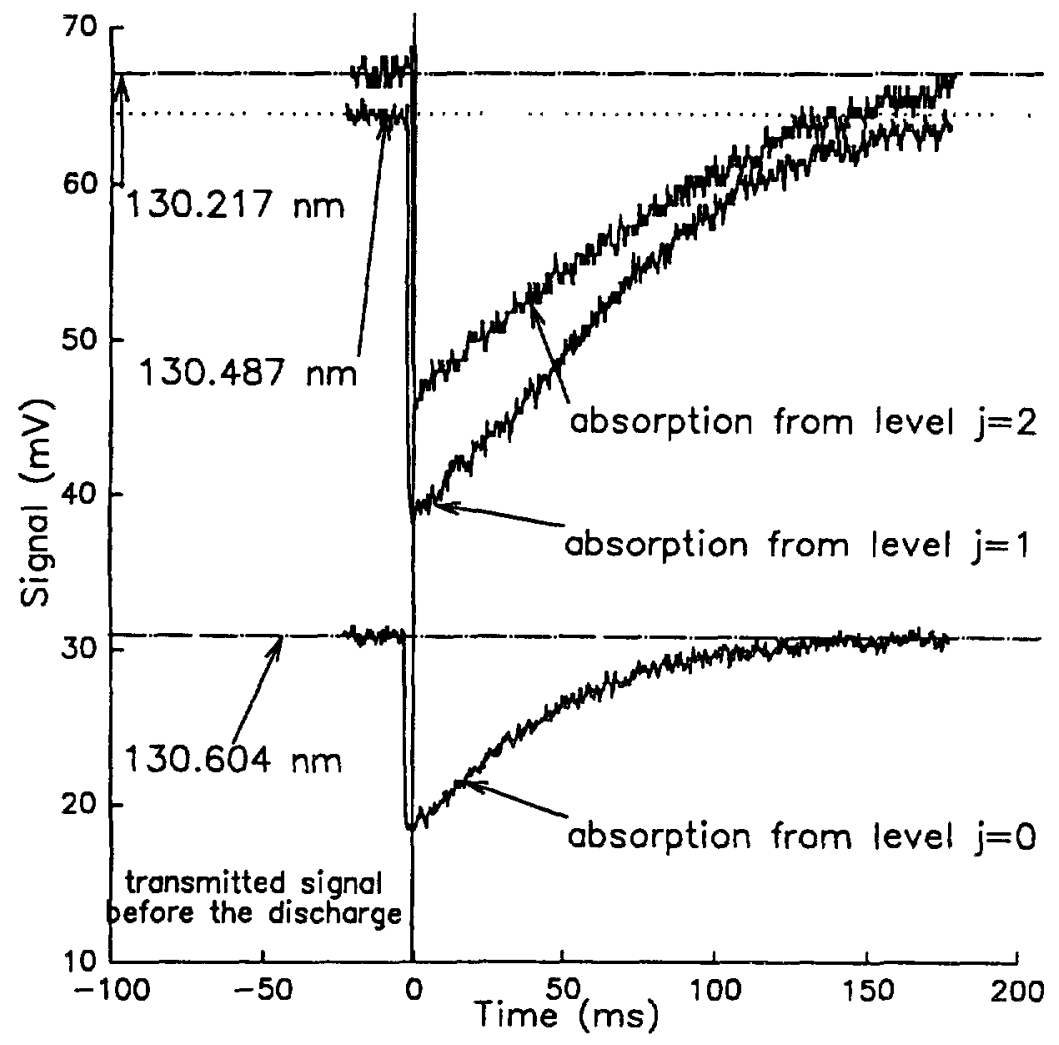

Fig. 5. - Transmitted signal through the discharge tube for the three lines. The instant $t=0$ corresponds to the end of the discharge. Because of the time scale, the discharge ( $30 \mu \mathrm{s}$ width) is not visible. 
In this expression, $\sigma_{X}(\lambda)$ is the absorption cross section on the molecular ground state given in [34] and reported in table $\mathrm{I} .\left[\mathrm{O}_{2}(\mathrm{X})\right](t<0)$ is the initial density of molecules on the ground state. $L$ is the length of the absorbing medium equal to $50 \mathrm{~cm} . F(\lambda)$ is the apparatus function and $I_{0}(\lambda)$ is the incident intensity emitted by the source (Fig. 3 ).

Table I. - Data used for the calibration.

\begin{tabular}{|c|c|c|c|c|c|}
\hline Level (J) & $\begin{array}{c}\text { Statistical } \\
\text { Weight } \mathrm{g}_{\mathrm{J}}\end{array}$ & $\Delta \mathrm{E}_{\mathrm{j}}$ in $\mathrm{K}$ & $\lambda$ in $\mathrm{nm}$ & $\begin{array}{c}\sigma_{\mathrm{x}}(\lambda) \text { in } \\
\mathrm{cm}^{2}\end{array}$ & $\begin{array}{c}\text { Oscillator } \\
\text { Strength } \mathrm{f}\end{array}$ \\
\hline 2 & 5 & 0 & 130.217 & $4.19 \times 10^{-19}$ & 0.048 \\
\hline 1 & 3 & 228.6 & 130.487 & $3.74 \times 10^{-19}$ & 0.048 \\
\hline 0 & 1 & 317.8 & 130.604 & $3.56 \times 10^{-19}$ & 0.048 \\
\hline
\end{tabular}

During the time afterglow, molecular and atomic ground states both absorb incident light. The transmitted signal can be expressed as :

$$
I_{\mathrm{T}}(\lambda, t)=\int_{-\infty}^{+\infty} I_{0}(\lambda-y) F(y) \exp \left(-\sigma_{\mathrm{X}}(\lambda-y)\left[\mathrm{O}_{2}(\mathrm{X})\right](t) L-K(\lambda-y, t) L\right) \mathrm{d} y
$$

where $K(\lambda, t)$ is the absorption coefficient of the atomic line. Here, due to the recombination of atomic oxygen during the afterglow, the density of molecules on the ground state is time dependent.

The phenomenon of resonant absorption for atomic transitions is well described in [35], and its application to an atomic density measurement in a steady state oxygen discharge is described in [23]. Therefore we only briefly explain the results used for the calibration.

The coefficient for atomic absorption can be written as the product of two factors [35] :

$$
K(\lambda)=K_{0} P(\lambda)
$$

where the first factor $K_{0}$ gives the value of the absorption coefficient for the central wavelength $\lambda_{0}$ of the emitted line and $P(\lambda)$ is the shape of the absorption line.

Within our experimental conditions $(P \leqslant 5$ Torr ), the effect of the pressure broadening on the absorption profile can be neglected [36]. The shape of absorption line is then given by the convolution of the Doppler broadening with the Lorentzian profile of the natural broadening. Since we assume a fixed gas temperature $T=300 \mathrm{~K}$, the Doppler broadening is time independent. The time independent Voigt profile is then calculated using the following formula :

$$
P(\nu)=\frac{a}{\pi} \int_{-\infty}^{+\infty} \frac{\exp \left(-x^{2}\right)}{a^{2}+(w-x)^{2}} \mathrm{~d} x
$$

with

$$
a=\frac{\Delta \nu_{\mathrm{N}}}{\Delta \nu_{\mathrm{D}}} \sqrt{\ln (2)}
$$

and

$$
w=\frac{\left(\nu-\nu_{0}\right)}{\Delta \nu_{D}} 2 \sqrt{\ln (2)}
$$


where $\Delta \nu_{\mathrm{N}}$ and $\Delta \nu_{\mathrm{D}}$ are respectively the natural and the Doppler broadening and $\nu_{0}$ is the central frequency of the absorption line.

For a Voigt profile, the absorption coefficient at the central wavelength of the line is given by $[35]$ :

$$
K_{0}=\left(\frac{e^{2}}{4 \pi \varepsilon_{0} m_{\mathrm{e}} c}\right)\left(\frac{1}{\Delta \nu_{\mathrm{D}}}\right) 2 \sqrt{\pi \ln (2)} f\left[\mathrm{O}\left({ }^{3} \mathrm{P}_{J}\right)\right]
$$

where $f$ is the oscillator strength of the line reported in table $\mathrm{I},\left[\mathrm{O}\left({ }^{3} \mathrm{P}_{J}\right)\right]$ is the density of absorbing atoms, $m_{\mathrm{e}}$ and $e$ are the mass and the charge of the electron, $\varepsilon_{0}$ is the vacuum permittivity and $c$ the light speed.

In order to take into account the time evolution of the molecular ground state density in the transmitted signal during the afterglow (Eq. (3)), the pressure is assumed to be constant. So the density of molecular ground state at the time $t$ of the afterglow is given by :

$$
\left[\mathrm{O}_{2}(\mathrm{X})\right](t)=\left[\mathrm{O}_{2}(\mathrm{X})\right](t<0)-[\mathrm{O}](t)
$$

where

$$
[O](t)=\sum_{l=0}^{\prime=2}\left[O\left({ }^{3} P_{j}\right)\right](t)
$$

The population of atoms on each sub-level of the ground state is supposed to be given by a Boltzmann distribution at temperature $T$ :

$$
\left[O\left({ }^{3} \mathrm{P}_{J}\right)\right]=\left(\frac{g_{J}}{g_{2}}\right)\left[O\left({ }^{3} \mathrm{P}_{2}\right)\right] \exp \left(-\frac{\Delta E_{J}}{k T}\right)
$$

where $\Delta E_{J}=E_{J}-E_{2}$ and $g_{J}$ is the statistical weight of level $J$.

Fixing the total atomic density on the ground state and taking into account the weak overlapping seen in figure 4 , we can calculate numerically the ratio $R_{\text {calc }}^{(/)}(\lambda)$ for the component $J$ as a function of the density on the corresponding sub-level $J$. Those calculations can be simplified assuming that the absorption cross section by molecular ground state $\sigma_{X}(\lambda)$ is constant for a wavelength range equal to the emission line width. Then, $R_{\text {calc }}^{(J)}(\lambda)$ is given by :

$$
R_{\text {calc }}^{(J)}(\lambda)=\exp \left(\sigma_{\mathrm{X}}^{J}(\lambda)[\mathrm{O}] L\right)\left(\frac{\sum_{j=0}^{2} \int_{-\infty}^{+\infty} I_{0}^{J}(\lambda-y) F(y) \exp \left(-K_{0} P(\lambda-y) L\right) \mathrm{d} y}{\sum_{i=0}^{2} \int_{-\infty}^{+\infty} I_{0}^{J}(\lambda-y) F(y) \mathrm{d} y}\right)
$$

where $F(\lambda)$ is centred on the wavelength of the considered component.

Figure 6 presents the so calculated ratio $R_{\text {calc }}^{(2)}(\lambda=130.217 \mathrm{~nm}), R_{\text {calc }}^{(1)}(\lambda=130.487 \mathrm{~nm})$ and $R_{\text {calc }}^{(0)}(\lambda=130.604 \mathrm{~nm})$ as functions of the density of each sub-level $\left[\mathrm{O}\left({ }^{3} \mathrm{P}_{2}\right)\right],\left[\mathrm{O}\left({ }^{3} \mathrm{P}_{1}\right)\right]$ and $\left[\mathrm{O}\left({ }^{3} \mathrm{P}_{0}\right)\right]$ respectively. All the required data for those calculations are reported in table $\mathrm{I}$.

For the low value of $R_{\text {calc }}^{(J)}(\lambda)$ (strong absorption), it is not possible to measure atomic density higher than an upper limit. However, within our experimental conditions, for atomic densities lower than $10^{15} \mathrm{~cm}^{-3}$ the accuracy of the deduced densities during the afterglow is still good. Reciprocally, for densities lower than $10^{11} \mathrm{~cm}^{-3}$ a small variation of density leads to a strong variation in $R_{\text {calc }}^{(J)}(\lambda)$. The accuracy is then determined by the signal over noise ratio. Typically, densities under $2 \times 10^{10} \mathrm{~cm}^{-3}$ are uncertain. 


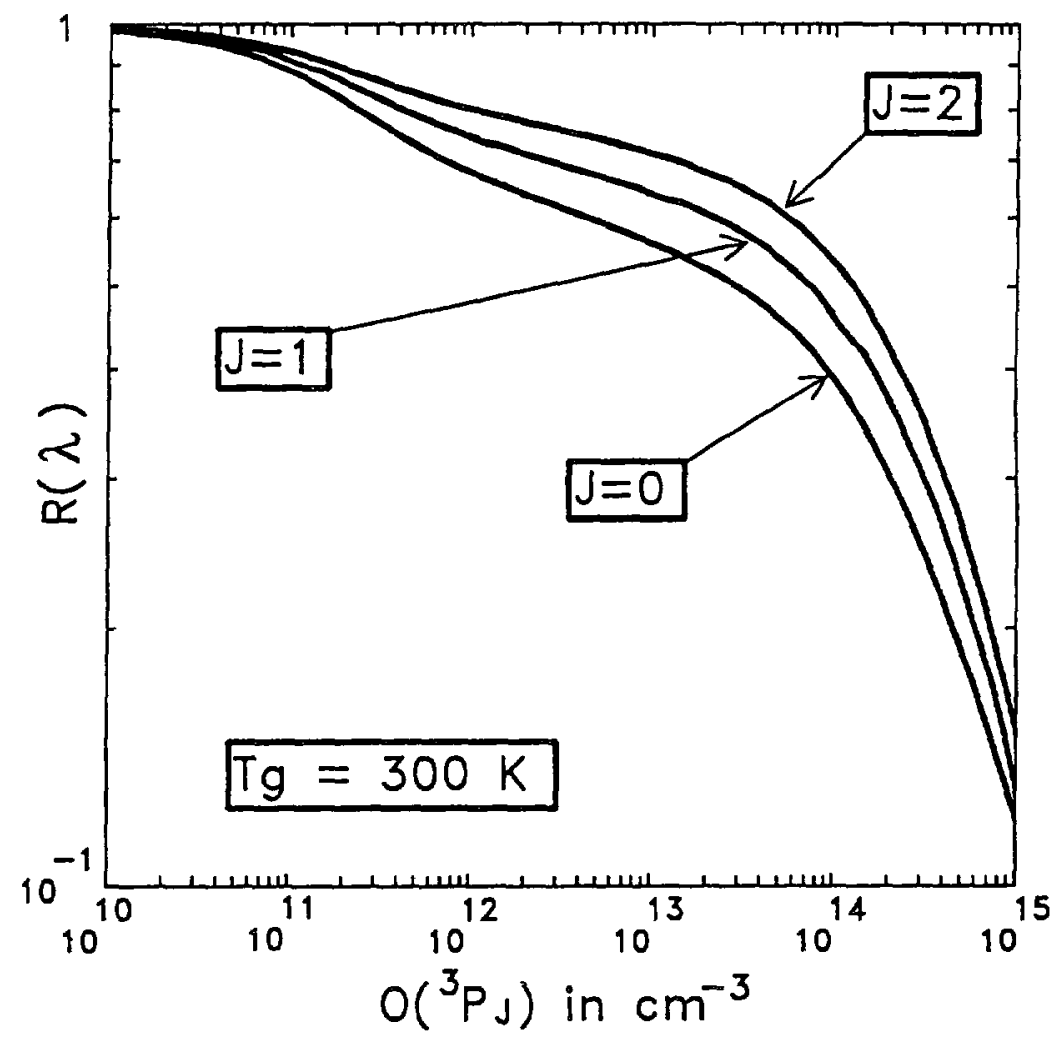

Fig. 6. $-R_{\text {calc }}^{(2)}(\lambda=130.217 \mathrm{~nm}), R_{\text {calc }}^{(1)}(\lambda=130.487 \mathrm{~nm})$ and $R_{\text {calc }}^{(0)}(\lambda=130.604 \mathrm{~nm})$ as functions of $\left[\mathrm{O}\left({ }^{3} \mathrm{P}_{2}\right)\right],\left[\mathrm{O}\left({ }^{3} \mathrm{P}_{1}\right)\right]$ and $\left[\mathrm{O}\left({ }^{3} \mathrm{P}_{0}\right)\right]$ respectively. The temperature of gas is assumed to be $T=300 \mathrm{~K}$.

The hypothesis of a Boltzmann equilibrium for the sub-levels distribution made in (11) is not a critical point for the calibration under our experimental conditions. Indeed, we detect each component of the atomic triplet with a good resolution (Fig. 4) and then, the population of each sub-level can be deduced from $R_{\text {calc }}^{(J)}(\lambda)$ for the corresponding component. But the hypothesis of a Boltzmann equilibrium is used for the calculation of molecular ground state density. Under our experimental conditions (short pulse width and low current), molecular dissociation stays low. The hypothesis of constant pressure (Eqs. (9) and (10)) leads to the correction factor $\exp \left(\sigma_{\mathrm{X}}[\mathrm{O}] L\right)$. This factor does not exceed 1.02. This correction factor can be neglected in comparison with experimental fluctuations.

The influence of the long life species $\mathrm{O}_{3}$ and $\mathrm{O}_{2}\left({ }^{1} \Delta_{\mathrm{g}}\right)$ on the calibration must now be discussed. The absorption of incident light by these two species can be taken into account in the transmitted signal $I_{\mathrm{T}}(\lambda, t)$ given in (3) by multiplying this expression by a factor $\exp \left(-\sigma_{\Delta}\left[\mathrm{O}_{2}\left({ }^{l} \Delta_{\mathrm{g}}\right)\right](t) L-\sigma_{\mathrm{O}_{3}}\left[\mathrm{O}_{3}\right](t) L\right)$. Here, $\sigma_{\lrcorner}$and $\sigma_{\mathrm{O}_{3}}$ are the absorption cross sections by $\mathrm{O}_{2}\left({ }^{1} \Delta_{\mathrm{g}}\right)$ and $\mathrm{O}_{3}$ respectively. These cross sections are supposed to be constant on a wavelength range equal to the emission line width. The expression of molecular ground state density at instant $t$ given in (9) must also be corrected and becomes :

$$
\left[\mathrm{O}_{2}(\mathrm{X})\right](t)=\left[\mathrm{O}_{2}(\mathrm{X})\right](t<0)-[\mathrm{O}](t)-\left[\mathrm{O}_{2}\left({ }^{\mathrm{l}} \Delta_{\mathrm{g}}\right)\right](t)-\left[\mathrm{O}_{3}\right](t) .
$$

The pulses repetition frequency is low (from $0.1 \mathrm{~Hz}$ to $1 \mathrm{~Hz}$ ) and because of the flux, the gas is 
changed between two pulses, then, $\mathrm{O}_{2}\left({ }^{1} \Delta_{\mathrm{g}}\right)$ and $\mathrm{O}_{3}$ do not have any influence on the expression of the transmitted signal before the discharge $I_{\mathrm{T}}(\lambda, t<0)$ given in (2). According to these remarks, the ratio $R_{\text {calc }}^{(I)}(\lambda)$ has to be multiplied by a factor :

$$
\exp \left(\left(\sigma_{\mathrm{X}}-\sigma_{\mathcal{J}}\right)\left[\mathrm{O}_{2}\left({ }^{\prime} \Delta_{\mathrm{g}}\right)\right](t) L\right) \times \exp \left(\left(\sigma_{\mathrm{X}}-\sigma_{\mathrm{O}_{3}}\right)\left[\mathrm{O}_{3}\right](t) L\right) .
$$

From the values of $\sigma_{\lrcorner}$and $\sigma_{\mathrm{X}}$ published in [34], an upper limit of the first exponential term can be evaluated assuming a constant value for $\left[\mathrm{O}_{2}\left({ }^{l} \Delta_{\mathrm{g}}\right)\right]$ during the afterglow. If we suppose a maximum density $\left[\mathrm{O}_{2}\left({ }^{1} \Delta_{\mathrm{g}}\right)\right]=10^{15} \mathrm{~cm}^{-3}$, the maximum value for the first exponential term is 1.02. So $\mathrm{O}_{2}\left({ }^{1} \Delta_{\mathrm{g}}\right)$ does not have a strong influence on the calibration. Similarity, an upper limit for the second exponential term is obtained assuming a maximum value for ozone density $\left[\mathrm{O}_{3}\right]=10^{14} \mathrm{~cm}^{-3}$ The absorption cross section by $\mathrm{O}_{3}$ at $130 \mathrm{~nm}$ is $\sigma_{\mathrm{O}_{3}}=1.24 \times 10^{-17} \mathrm{~cm}^{2}$ [37]. The second exponential term is then 0.94 . We can see in figure 6 that this effect can be neglected for low values of $R_{\text {calc }}^{(J)}(\lambda)$ (high atomic density). For the high value of $R_{\text {calc }}^{(j)}(\lambda)$, the fact that absorption by ozone is not included in the calibration can involve an overestimation of the atomic density. This overestimation could reach a factor 5 for atomic densities under $2 \times 10^{11} \mathrm{~cm}^{-3}$ assuming an ozone density of $10^{14} \mathrm{~cm}^{-3}$. The contribution of ozone absorption is overestimated in this calculation but we have to keep in mind that atomic densities could be significantly overestimated at the end of the afterglow.

\section{Experimental results.}

From the ratio $R_{\text {exp }}(\lambda, t)$ and using the results of the calibration plotted in figure 6 , we obtain the absolute density for each level of the ground state $\mathrm{O}\left({ }^{3} \mathrm{P}_{J}\right)$. Typical results are shown in the semi logarithmic plots figure $7 \mathrm{a}$ for $\mathrm{O}\left({ }^{3} \mathrm{P}_{2}\right)$, figure $7 \mathrm{~b}$ for $\mathrm{O}\left({ }^{3} \mathrm{P}_{1}\right)$ and figure $7 \mathrm{c}$ for $\mathrm{O}\left({ }^{3} P_{0}\right)$.

From these figures it is clear that the evolution of atomic density is not a single exponential decay. In order to determine the frequencies associated with atomic density decay we use a non linear regression. A very good fit is obtained with a sum of two exponential decays :

$$
\left[\mathrm{O}\left({ }^{3} \mathrm{P}_{J}\right)\right](t)=C_{\mathrm{f}} \exp \left(-\nu_{\mathrm{f}} t\right)+C_{\mathrm{s}} \exp \left(-\nu_{\mathrm{s}} t\right)
$$

where $C_{\mathrm{t}}$ and $C_{\mathrm{s}}$ are the contribution of the fastest and the slowest decay respectively. $\nu_{\mathrm{f}}$ and $\nu_{\mathrm{s}}$ are the associated frequencies. The results of the non linear regression are reported in figures $7 \mathrm{a}, 7 \mathrm{~b}$ and $7 \mathrm{c}$. Figures $8 \mathrm{a}$ and $8 \mathrm{~b}$ present the so deduced $\nu_{t}$ and $\nu_{\mathrm{s}}$ frequencies as functions of pressure.

For a fixed pressure, the values of the so determined frequencies $\nu_{f}$ and $\nu_{s}$ presented in figures $8 \mathrm{a}$ and $8 \mathrm{~b}$ are dispersed. For instance, concerning $\nu_{\mathrm{f}}$, for a pressure around 0.3 Torr, the values range from $120 \mathrm{~Hz}$ to $290 \mathrm{~Hz}$. This scattering does not result from a bad accuracy of the fit. The error on the calculated frequencies attributed to the fit does not exceed ten per cent. That discrepancy is due to discharge reproducibility. Because of these experimental fluctuations, $\nu_{\mathrm{t}}$ and $\nu_{\mathrm{s}}$ seem not to depend on the discharge current and no difference between the sub-levels is observed. For the same reason, it is impossible to find a dependence of the ratio $C \sqrt{ } C_{\mathrm{f}}$ with the pressure or the discharge current.

The obtained densities at the end of the discharge $(t=0)$ shown in figures $7 \mathrm{a}, 7 \mathrm{~b}$ and $7 \mathrm{c}$ are not in agreement with a Boltzmann distribution at $300 \mathrm{~K}$. The acquisitions of transmitted signals for the three lines are not simultaneous but are the results of three independent experiments. So these results are affected by the discharge reproducibility.

Since the main loss process of atomic oxygen is known to be the loss at the wall, $\nu_{\mathrm{f}}$ can be attributed to that process. 

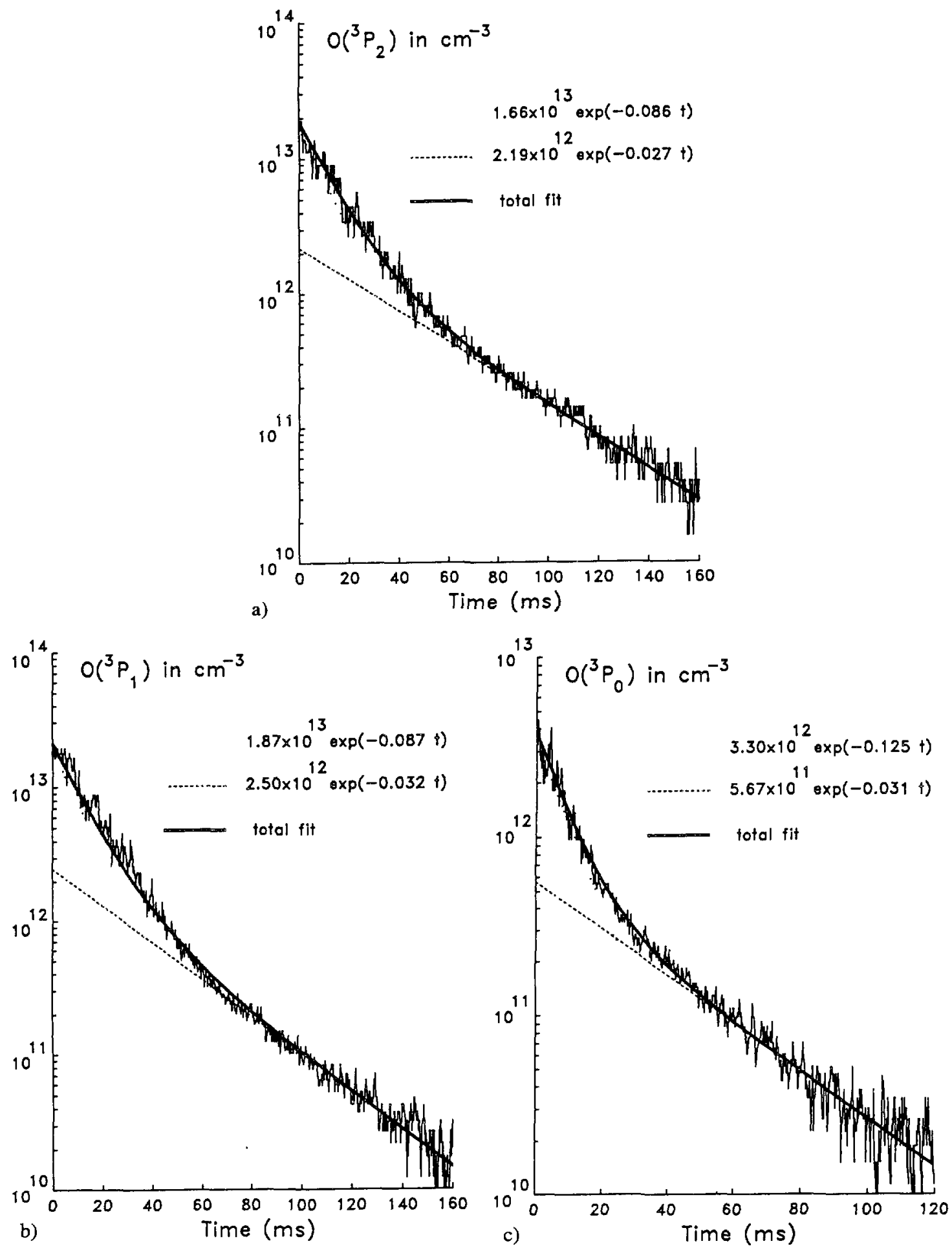

Fig. 7. - a) $\left[\mathrm{O}\left({ }^{3} \mathrm{P}_{2}\right)\right](t)$ in the afterglow for $P=0.6 \mathrm{Torr}, I=200 \mathrm{~mA}$ and a pulse width of $30 \mu \mathrm{s}$. b) $\left[\mathrm{O}\left({ }^{3} \mathrm{P}_{1}\right)\right](t)$ in the afterglow for $P=0.6 \mathrm{Torr}, I=200 \mathrm{~mA}$ and a pulse width of $30 \mu \mathrm{s}$. c) $\left[\mathrm{O}\left({ }^{3} \mathrm{P}_{0}\right)\right](t)$ in the afterglow for $P=0.6$ Torr, $I=200 \mathrm{~mA}$ and a pulse width of $30 \mu \mathrm{s}$. 


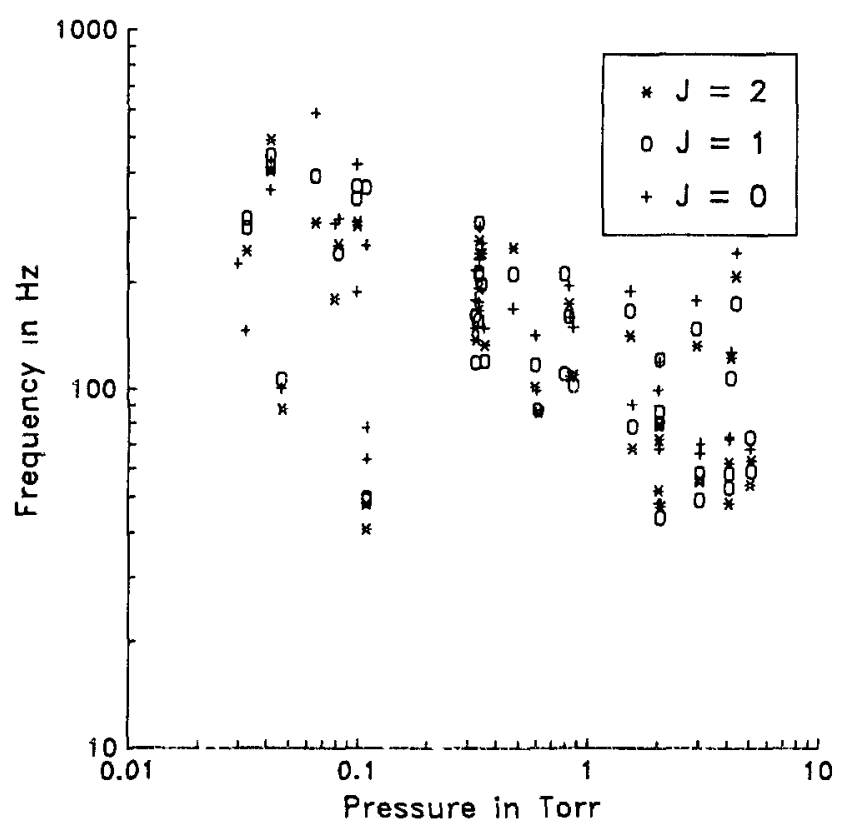

a)

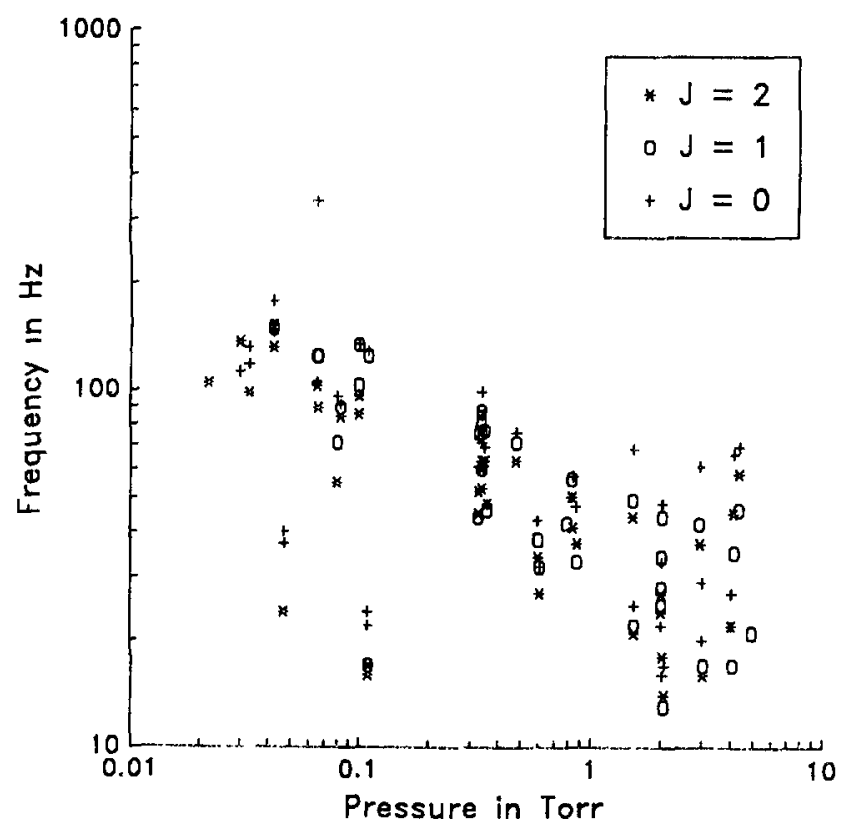

b)

Fig. 8. - a) The fast frequency $\nu_{f}$ as a function of pressure. b) The slow frequency $\nu_{\text {, as a function of }}$ pressure. 
For the part of the measurements for which the mean free path is small in comparison with the tube radius $r$, the total time taken for recombination can be approximated as the sum of the time taken to reach the wall $\tau_{1}$ and the time $\tau_{2}$ needed for recombination when the atom is a distance from the wall equal to the mean free path [38]. Then $\nu_{f}$ can be written as:

$$
\nu_{\mathrm{f}}=\frac{1}{\tau_{1}+\tau_{2}}=\frac{1}{\frac{r^{2} P}{8 D_{0}}+\frac{2 r}{\gamma \bar{u}}}
$$

where $D_{0}$ is the diffusion coefficient at 1 Torr, $P$ is the pressure in Torr and $\bar{u}$ is the atoms mean velocity.

In our case, this last formula is valid for a pressure higher than 0.5 Torr. Because of the discrepancy of the measurements, we cannot find a pressure dependence of $\nu_{\mathrm{f}}$ in the 0.5 to 5 Torr range.

From the results in this pressure range, we calculate a mean value $\bar{\nu}_{\mathrm{f}}=100 \mathrm{~Hz}$. From the equation [14] we see that $\frac{1}{\bar{\nu}_{\mathrm{f}}}=\tau_{1}+\tau_{2}=10^{-2} \mathrm{~s}$.

The diffusion coefficient of atomic oxygen in $\mathrm{O}_{2}$ is $D_{0}=222 \mathrm{~cm}^{2} \mathrm{~s}^{-1}$ at 1 Torr [39]. Within our experimental conditions, $\tau_{1}(\mathrm{~s}) \approx 3 \times 10^{-4} P$ (Torr), then, for $P=5$ Torr, $\tau_{1} \approx 1.5 \times 10^{-3} \mathrm{~s}$. So the correction due to diffusion can be neglected in comparison with the experimental fluctuations. So we can determine the recombination probability $\gamma$ assuming that $\bar{\nu}_{\mathrm{f}}=\frac{1}{\tau_{2}}=\frac{\gamma \bar{u}}{2 r}$ The so obtained value is :

$$
\gamma=(2.4 \pm 1.1) \times 10^{-3}
$$

$\Delta \gamma$ is estimated using the standard deviation of $\nu_{\mathrm{f}}$.

The interpretation of the measurements for pressure under 0.5 Torr is difficult. When the mean free path is not small in comparison with the tube radius, the wall cannot be considered as a plane surface and the assumptions made in relation (14) are not valid. Moreover, if the number of collisions in the bulk of gas is not sufficient to thermalize the atoms, their mean velocity could increase when pressure decreases. The recombination probability increases while atomic velocity increases because of the activation threshold [43]. As the loss frequency $\nu_{\mathrm{f}}$ is an increasing function of $\gamma$ and $\bar{u}$, this could explain why $\nu_{\mathrm{f}}$ increases while the pressure decreases.

Interpretation of the slowest decay $\nu_{f}$ is not easy. However, qualitative interpretations of this decay will be brought into the discussion in terms of eventual atomic gain.

\section{Discussion.}

Some published values of the recombination probability at the wall $\gamma$ for oxygen atoms on pyrex are reported in table II. Most of them concern pyrex kept out of the discharge zone. The values published in $[21,23,28]$ are estimated for pyrex within a D.C. discharge. They are obtained assuming the balance between the dissociation by electronic collisions, which is calculated using a Boltzmann code, and the losses at the wall. $\gamma$ is deduced by fitting experimental atomic densities measured by resonant V.U.V. absorption spectroscopy [21, 23 , 28] or actinometry [21]. Our value of $\gamma$ is close to these results. The published values of $\gamma$ within discharge at $T=300 \mathrm{~K}$ are higher than for pyrex in flowing afterglow. The differences between recombination in discharges and in afterglow are not explained yet : for 
Table II. - Published values of the recombination probability at a pyrex wall for oxygen atoms.

\begin{tabular}{|c|c|c|c|}
\hline$\gamma$ & Excitation & Medium & ref. \\
\hline $1.2 \times 10^{-4}$ & $\mathrm{RF}$ & $\begin{array}{l}\text { Flowing } \\
\text { afterglow }\end{array}$ & [9] \\
\hline $3.1 \times 10^{-5}$ & RF & $\begin{array}{l}\text { Flowing } \\
\text { afterglow }\end{array}$ & [40] \\
\hline $2 \times 10^{-5}$ & Pyrolysis & $\begin{array}{l}\text { Flowing } \\
\text { afterglow }\end{array}$ & [32] \\
\hline $1.2 \times 10^{-4}$ & RF & $\begin{array}{l}\text { Flowing - - } \\
\text { afterglow }\end{array}$ & [41] \\
\hline $1.6 \times 10^{-4}$ & Microwave & $\begin{array}{l}\text { Flowing } \\
\text { afterglow }\end{array}$ & [42] \\
\hline $5 \times 10^{-4}$ & Microwave & $\begin{array}{l}\text { Flowing } \\
\text { afterglow }\end{array}$ & [14] \\
\hline $4.6 \times 10^{-4}$ & D.C & $\begin{array}{l}\text { Flowing } \\
\text { afterglow }\end{array}$ & [16] \\
\hline $9.2 \times 10^{-5}$ & RF & $\begin{array}{c}\text { Flowing } \\
\text { afterglow }\end{array}$ & [12] \\
\hline$(1.2-0.33) \times 10^{4}$ & $\mathrm{RF}$ & $\begin{array}{l}\text { Flowing } \\
\text { afterglow }\end{array}$ & [11] \\
\hline $2.1 \times 10^{-3}$ & D.C & $\begin{array}{l}\text { Within the } \\
\text { discharge }\end{array}$ & [23] \\
\hline $5 \times 10^{-3}$ & D.C & $\begin{array}{l}\text { Within the } \\
\text { discharge }\end{array}$ & [28] \\
\hline $\begin{array}{c}1.53 \times 10^{-17} \cdot \mathrm{T}^{56} \\
320 \mathrm{~K} \leq \mathrm{T} \leq 450\end{array}$ & D.C & $\begin{array}{l}\text { Within the } \\
\text { discharge }\end{array}$ & [21] \\
\hline $2.4 \times 10^{-3}$ & $\begin{array}{c}\text { Pulsed } \\
\text { discharge }\end{array}$ & Time afterglow & $\begin{array}{c}\text { present } \\
\text { work }\end{array}$ \\
\hline
\end{tabular}

atomic densities around $10^{15} \mathrm{~cm}^{-3}$, the dominant recombination process is the Rideal [43] mechanism involving the collision of a gaseous atom with an adatom. The recombination probability is then proportional to the number of adatoms per unit surface area. From the theory of atomic recombination at the surface [43], it seems that for a temperature ranging from $250 \mathrm{~K}$ to $700 \mathrm{~K}$ (including temperature reached in discharges and afterglows), all the sites are covered by adatoms, so $\gamma$ does not depend on the dentisy of gaseous atoms. In that case, $\gamma$ is an increasing function of the temperature. This last point is well observed in [21]. But following that theory, in a discharge at $300 \mathrm{~K}, \gamma$ should be equal to $\gamma$ in flowing afterglow.

The difference between $\gamma$ within discharge and $\gamma$ in afterglow could be due to a modification of the surface state of the wall when it is submitted to the discharge. The effect of surface bombardment by heavy charges particles, accelerated in the sheath field is not well known. However, we think that this exposure only has reversible consequences on the recombination. As a matter of fact we do not have noticed permanent modification of atomic decays during the whole measurement process. So irreversible modifications like roughness alteration could be rejected. The plasma exposure could improve the cleanliness of the surface by removing adsorbed impurities and increasing the number of oxygen adatoms that could increase the 
recombination at the wall. The influence of the poisoning of the surface by impurities such as water or metallic atoms sputtered by the electrodes is not easily calculable and the discussion about these problems is still open.

Interpretation of the slowest decay is not easy because of the possible absorption by ozone at the end of the afterglow which could have an influence on the atomic decay. Apart from that, it seems that the hypothesis of atomic gain during the afterglow could be brought up.

The slowest decay observed in the time evolution of atomic ground state could bring about a second explanation of those variations of $\gamma$ values between discharges and flowing afterglow. In the 0.5 Torr to 5 Torr pressure range, decay has a mean characteristic frequency $\bar{\nu}$, equal to $35 \mathrm{~Hz}$. This slower decay could be caused by a gain of atoms during the time afterglow. According to the time evolution of atomic density given by equation (13) and assuming that this gain $G(t)$ satisfies the equation :

$$
\frac{\partial[\mathrm{O}](t)}{\partial t}=-\nu_{\mathrm{f}}[\mathrm{O}](t)+G(t)
$$

we obtain the time evolution :

$$
G(t)=\left(\nu_{\mathrm{f}}-\nu_{\mathrm{s}}\right) C_{\mathrm{s}} \exp \left(-\nu_{\mathrm{s}} t\right)
$$

For instance, for the measurements presented in figures $7 \mathrm{a}, 7 \mathrm{~b}$ and $7 \mathrm{c}$, this gain is approximately equal to $3.5 \times 10^{14} \mathrm{~cm}^{-3} \mathrm{~s}^{-1}$ at the instant $t=0$.

This gain could come from weakly adsorbed atoms. This kind of adatoms could easily leave the surface of the wall during the afterglow with a characteristic frequency equal to $35 \mathrm{~Hz}$. An initial density at the wall of those adatoms equal to $2 \times 10^{12} \mathrm{~cm}^{-2}$ would be enough to give the observed gain. However, this process is controlled by the properties of the surface and assumes a very low heat of adsorption. So it is difficult to prove this assumption because it requires a very good knowledge of the surface state of the wall.

This gain could also be due to reactions in the bulk of gas. The kinetics ruling the evolutions of long life species such as $\mathrm{O}_{2}\left({ }^{1} \Delta_{\mathrm{g}}\right), \mathrm{O}_{2}\left({ }^{1} \Sigma_{\mathrm{g}}^{+}\right), \mathrm{O}_{3}$ and $\mathrm{O}$ in afterglows are complex, because these species are strongly coupled with numerous reactions. However, concerning the atoms, it seems that the reactions reported in table III are the most efficient.

The reaction $\mathrm{R} I$ could lead to an atomic gain via the quenching of $O\left({ }^{1} \mathrm{D}\right)$. However, the coefficient $k_{\mathrm{R} I}$ reported in [44] by Eliasson is controversial and seems to be strongly overestimated. So the reactions R3 and R4 could also give significative atomic gain during the afterglow. This gain has a time evolution ruled by the decay of $\mathrm{O}\left({ }^{\prime} \mathrm{D}\right), \mathrm{O}_{2}\left({ }^{\prime} \Sigma_{\mathrm{g}}^{+}\right)$, $\mathrm{O}_{2}\left({ }^{\prime} \Delta_{\mathrm{g}}\right), \mathrm{O}_{3}$. These last two species are known for their long lifetime in afterglows. This gain could appear as the slower decay in our experimental results. However, its contribution strongly depends on the initial densities. No measurements of these species under experimental conditions close enough to ours have been published so far. Moreover, the estimation of the time dependence of this gain requires a solvation of the complete kinetics during the afterglow which must take into account all the reactions involving these species.

However, the hypothesis of atomic gain that we propose here seems to be in agreement with experimental observations in flowing afterglow published in [11]. In this work, the spatial decay of atomic oxygen ground state density is measured in the flowing afterglow of a RF discharge as a function of the RF power. These measurements are done for distances from the discharge between $50 \mathrm{~cm}$ and $150 \mathrm{~cm}$. Pressure is fixed at 1 Torr and the velocity of gas is $55 \mathrm{~cm} . \mathrm{s}^{-1}$. The slope of the spatial decay of atomic density [O] becomes smaller as power increases from $200 \mathrm{~W}$ to $600 \mathrm{~W}$ and the ratio $\left[\mathrm{O}\left({ }^{\prime} \mathrm{D}\right)\right] /[\mathrm{O}]$ increases from $50 \%$ to $80 \%$ at $60 \mathrm{~cm}$ from discharge. The authors mention that $\mathrm{O}_{2}\left({ }^{1} \Delta_{\mathrm{g}}\right)$ is found as a major product in the downstream flow and that metastable $\mathrm{O}_{2}\left({ }^{1} \Sigma_{\mathrm{g}}^{+}\right)$is observed existing up to $150 \mathrm{~cm}$ in the flow. 
Table III. - Reactions for creation and loss of atomic oxygen in the time afterglow.

\begin{tabular}{|c|c|c|c|}
\hline reaction & & $\mathbf{k}\left(\mathrm{cm}^{3} \mathrm{~s}^{-1}\right)$ & ref. \\
\hline$\left.O_{2}\left(\Delta_{2}\right)+O_{3}-O^{1} D\right)+O_{2}+O_{2}$ & R1 & $10^{-11}$ & [44] \\
\hline$\left.O^{1} D\right)+O_{2}+O+O_{2}$ & $\mathrm{R} 2 \mathrm{a}$ & $3 \times 10^{-11}$ & [45] \\
\hline$\left.O^{1} D\right)+O_{2}+O+O_{2}\left({ }^{1} \Delta_{8}\right)$ & R2 $2 \mathrm{~b}$ & $7 \times 10^{-11}$ & [46] \\
\hline$\left.O{ }^{1} D\right)+O_{2}+O+O_{2}\left({ }^{1} D_{2}\right)$ & R2c & $7.4 \times 10^{-11}$ & [47] \\
\hline$O_{2}\left(\Delta_{8}\right)+O_{3}+O+O_{2}+O_{2}$ & R3 & $3.8 \times 10^{-15}$ & [48] \\
\hline$O_{2}\left({ }^{1} \Sigma_{8}^{+}\right)+O_{3}-O+O_{2}+O_{2}$ & R4 & $1.8 \times 10^{-11}$ & [48] \\
\hline$O+$ wall $-\frac{1}{2} O_{2}$ & R5 & $100 s^{-1}$ & $\begin{array}{l}\text { presen } \\
\text { work }\end{array}$ \\
\hline
\end{tabular}

Consequently, there could be a non negligible gain of $O$ along the flow and the spatial decay of atomic oxygen includes this gain. The fact that the slope decreases while the power increases could be due to an increase in molecular metastable states and $O\left({ }^{1} \mathrm{D}\right)$ populations which could increase atomic gain contribution in the spatial decay. This decay is obtained for times higher than $1 \mathrm{~s}$ and could correspond to our slowest decay $\nu_{\mathrm{s}}$. Therefore, this effect could explain a part of the differences in the values of $\gamma$ in flowing afterglow and in discharge. For instance, in [11], $\gamma$ is deduced from the spatial decay of [O]. As this decay could be not only due to losses at the wall but also could include gain process, $\gamma$ could be underestimated.

In the case of steady state D.C. discharges $[21,23,28]$ the gain of atomic ground state by the reaction $\mathrm{R} 1, \mathrm{R} 3$ and $\mathrm{R} 4$ can be neglected in front of the dissociation by electronic collisions. So, the calculated values of $\gamma$ published in $[21,23,28]$ are free from this effect. $\gamma$ that we determine from $\nu_{\mathrm{f}}$ is close to the one obtained in discharge because, to a certain extent, we have distinguished loss and possible gain by fitting the temporal evolution of atomic ground state density with a double exponential decay. 


\section{Conclusion.}

The association of time afterglow and time resolved resonant absorption spectroscopy constitute a good experimental technique allowing us to follow the time evolution of atomic ground state density. This technique does not require any addition of other species for titration which could perturb the afterglow. This first experimental value of $\gamma=2.4 \times 10^{-3}$ for pyrex under plasma exposure is in good agreement with the calculated values in steady state discharges conditions. This agreement is perhaps due to a similar surface state of the wall but also to the method we used for the determination of $\gamma$. Indeed, this method allows a relatively good distinction between gain and loss processes.

\section{Acknowledgments.}

We would like to thank F. Launay for her contribution to the measurements of line profiles with the $10 \mathrm{~m} \mathrm{V.U.V.} \mathrm{spectrometer} \mathrm{at} \mathrm{the} \mathrm{Observatoire} \mathrm{de} \mathrm{Meudon} \mathrm{(France)} \mathrm{and} \mathrm{Dr.} \mathrm{M.}$ Touzeau, Pr. M. Vialle and Dr. D. Pagnon for many helpful discussions concerning oxygen atoms.

\section{References}

[1] Cuthbertson J. W., Langer W. D. and Mutley R. W., Atomic Oxygen Beam Source for Orbital Envıronment Experiment, Mater. Manufacturing Processes 5 (1990) 387.

[2] Campargue R., Lebehot A. and Girard J. M., Sources d'Oxygène Atomique pour la Simulation de l'Environnement Spatial en Orbite Basse (150 à $600 \mathrm{~km}$ ), Ann. Chim Fr. 17 (1992) 347.

[3] Pietre S., Utilisation de l'Actinométrie comme Nouvelle Méthode d'Etudes des Mécanismes de Recombinaison Catalytique de l'Oxygène Atomique dans les Plasmas d'Air Hors Equilibre. Application au SiC-SiC Matériau Candidat au Système de Protection Thermique de l'Avion Spatial Hermès, Thèse, Université Paris VI (1990).

[4] Kwo J., Hong M.. Trevor D. J., Fleming R. M., White A. E., Farrow R. C., Kortan A. R. and Short K. T., In Situ Epitaxial Growth of $\mathrm{Y}_{1} \mathrm{Ba}_{2} \mathrm{Cu}_{3} \mathrm{O}_{7-}$, Films by Molecular Beam Epitaxy with an Activated Oxygen Source, Appl Phys. Lett. 53 (1988) 2683.

[5] Guymont O., LeDuc E., Pagnon D., Pointu A. M., Touzeau M.. Vialle M., Mercey B. and Murray H., Atomic Oxygen Radio Frequency Source and its Application to the Treatment of Mixed Valence Copper Oxide Thin Films, Plasma Sources Sci. Technol. 1 (1992) 175.

[6] Normand F., Marec J., Leprince Ph. and Granier A., Surface Treatment of Polypropylene by Oxygen Microwave Discharge, Mater. Sci. Eng. A 139 (1991) 103.

[7] Antonov E. E. and Popovich V. I., Recombination of Free O( $\left.{ }^{3} \mathrm{P}\right)$ Oxygen Atoms on an Electrically Conducting Glass Surface, Sor. Phys. Tech. Phys. 35 (1990) 1134.

[8] Kocian P.. Note on the Dissociation of Oxygen in a Low-Pressure Discharge Plasma, Phys Lett. 73 (1979) 17.

[9] Linnett J. W., Marsden F. R. S. and D. G. H., The Kinetics of the Recombination of Oxygen Atoms at a Glass Surface, Proc. R. Soc. A 234 (1956) 489.

[10] Piper L. G., Caledonia G. E. and Kennealy J. P., Rate Constants for Deactivation of $\mathrm{N}_{2}\left(\mathrm{~A}^{7} \Sigma_{u}^{+}, v^{\prime}=0,1\right)$ by $\mathrm{O}, J$. Chem Phys. 75 (1981) 2847.

[11] Wrickramanayaka S., Hosokawa N. and Hatanaka Y., Variation of the Recombınation Coefficient of Atomic Oxygen on a Pyrex Glass with Applied R. F. Power, Jnp J. Appl. Phys. 30 (1991) 2897.

[12] Wrickamanayaka S., Meikle S., Kobayashi T., Hosokawa N. and Hatanaka Y., Measurements of Catalytic Efficiency of Surface for the Removal of Atomic Oxygen using $\mathrm{NO}_{2}^{*}$ Continuum, $J$. Vac. Sci Technol. A 9 (1991) 2999. 
[13] Wrickamanayaka S., Meikle S., Sekigushı A., Hosokawa M. and Hatanaka Y., Characterization of Thermodynamically Non Equilibrium High Temperature Oxygen Plasma Downstream Region, J. Appl. Phys. 69 (1991) 6340.

[14] Brake M., Hınkle J., Asmussen J., Hawley M. and Kerber R., Dissociation and Recombination of Oxygen Atoms Produced in a Microwave Discharge, Plasma Chem. Plasma Process. 3 (1983) 63.

[15] Sabadil H., Biborosch L. and Koebe G., Zur O, Dissoziation in der Gleichstrmglimmentladung, Beitr. Plasmaphys. 15 (1975) 319.

[16] Sabadil H. and Pfau S., Measurement of the Degree of Dissociation in Oxygen D.C. Discharges : Comparison of the Ozone Method with the Wrede-Hartec Method, Plasma Chem. Plasma Process. 5 (1985) 67.

[17] Pollard J. E., Radio-Frequency Discharge Source for Beams of Atomic Nitrogen and Oxygen, Rev. Sci. Instrum. 62 (1992) 1771.

[18] Matijasevic V., Garwin E. L. and Hammond R. H.. Atomic Oxygen Detection by a Silver-Coated Quartz Deposition Monitor, Rev. Sci. Instrum. 61 (1990) 1747.

[19] Granier A., Pasquier S., Boisse-Laporte C., Darchicourt R., Leprince Ph. and Marec J., Characterization of a Low Pressure Oxygen Discharge Created by Surface Waves, J. Phys. $D$ Appl. Phys. 22 (1989) 1487.

[20] Roth P., Experimental Determination of Kinetic Coefficients with Significance in Hypersonic Flows, IUTAM Symposium on Aerothermochemistry of Spacecraft and Associated Hypersonic Flows, Marseille France (1992).

[21] Pagnon D., Etude de la Dissociation de $\mathrm{O}_{2}$ dans les décharges d'Oxygène. Application à la Réalisation de Sources d'Atomes, Thèse, Université, Paris XI (1992).

[22] DiMauro L. F., Gottscho R. A. and Miller T. A., Two-Photon Laser Induced Fluorescence Monitoring of O Atoms in a Plasma Etching Environment, J. Appl. Phys. 56 (1984) 2007.

[23] Gousset G., Panafieu P., Touzeau M. and Vialle M., Experimental Study of a D.C. Oxygen Glow Discharge by V.U.V. Absorption Spectroscopy, Plasma Chem. Plasma Process 7 (1987) 409.

[24] Ferreira C. M. and Gousset G., A Consistent Model of the Low Pressure Oxygen Positive Column, J. Phys. D : Appl. Phys. 24 (1991) 775.

[25] Gousset G., Ferreira C. M., Pinheiro M., Sà P. A., Touzeau M., Vialle M. and Loureiro J., Electron and Heavy Particles Kinetics in the Low Pressure Oxygen Positive Column, J. Phys. D : Appl. Phys. 24 (1991) 290.

[26] Vialle M., Touzeau M., Gousset G. and Ferreira C. M., Kinetics of $O(' S)$ and O('D) Metastable Atoms in a D.C. Oxygen Discharge, J. Phys. D : Appl. Phys. 24 (1991) 310.

[27] Ichikawa Y., Wu R. L. C. and Kaneda T., Theoretical and Experimental Characterization of Positive Column Plasma in Oxygen Glow Discharge, J. Appl. Phys 67 (1990) 108.

[28] Gousset G., Touzeau M., Vialle M. and Ferreira C. M., Kinetic Model of a D.C. Oxygen Glow Discharge, Plasma Chem. Plasma Process. 9 (1989) 189.

[29] Masek K. and Laska L., D.C. Glow Discharge in a Tube with the Walls of a Different Catalytic Activity, Czech. J. Phys. B 30 (1980) 805.

[30] Laska L., Masek K. and Ruzicka T., Numerical Analysis of a Glow Discharge in Oxygen, Czech. $J$. Phys. B 29 (1979) 498.

[31] Dettmer J. W., PhD Thesis, Discharges Processes in the Oxygen discharges. Air Force Institute of Technology (1978).

[32] Kaufman F. and Kelso J. R., $M$ Effect in the Gas-Phase Recombination of $O$ with $\mathrm{O}_{2}$, J. Chem. Phys. 46 (1967) 4541.

[33] Magne L., Etude du Singulet Métastable de l'Azote Moléculaire et des Atomes d'Oxygène dans les Décharges et Post-Décharges, Thèse, Université Paris XI (1991).

[34] Ogawa S. and Ogawa M., Absorption Cross Sections of $\mathrm{O}_{2}\left(\mathrm{a}^{\prime} \Delta_{\mathrm{g}}\right)$ and $\mathrm{O}_{2}\left(\mathrm{X}^{3} \Sigma_{\mathrm{g}}^{-}\right)$in the Region from 1087 to $1700 \AA$, Can. I Phys. 53 (1975) 1845.

[35] Mitchell A. C. J. and Zemansky M. W., Resonance Radiations and Excited Atoms (Cambridge University Press, Cambridge, 1971).

[36] Clyne M. A. A. and Piper L. G., Kinetic Spectroscopy in the Far Vacuum Ultraviolet, J. Chem Soc. Faradav. Trans. II 72 (1976) 2178. 
[37] Baulch D. L., Cox R. A., Crutzen P. J., Hampson Jr R. F., Keer J. A., Troe J. and Watson R. T., Evaluated Kinetic and Photochemical Data for Atmospheric Chemistry: Supplement I, $J$. Phys. Chem. Ref. Data 11 (1982) 327.

[38] Frimer A. A., Physical Aspects, Singlet $\mathrm{O}_{2}$ Vol. 1, (C.R.C. Press. Inc., 1985).

[39] Morgan J. E. and Schiff H. I., Diffusion Coefficients of O and N Atoms in Inert Gases, Can. J Chem. 42 (1964) 2300.

[40] Greaves J. C. and Linnett J. W., Recombination of Atoms at Surfaces. VI Recombination of Oxygen Atoms on Silica From $20^{\circ} \mathrm{C}$ to $600{ }^{\circ} \mathrm{C}$, Trans. Faraday. Soc 55 (1959) 1338.

[41] Bell A. T. and Kwong K., Dissociation of Oxygen in a Radio-Frequency Electrical Discharge, AIChE J. 18 (1972) 990.

[42] Bell A. T. and Kwong K., A Model for the Kinetic of Oxygen Dissociation in a Microwave Discharge, Ind. Eng Chem. Foundam 12 (1973) 90.

[43] Gelb A. and Kim S. K., Theory of Atomic Recombination on Surface, J. Chem. Phys. 55 (1971) 4935.

[44] Eliasson B. and Kogeelschatz U., Brown Boveri Forschungszentrum KLR 86-11 C. Basic Data for Modelling of Electrical Discharges in Gases: Oxygen (1986).

[45] Koroleva E. A. and Khvorostovskaya L. E., Processes of Metastable Level Deactivation in an Oxygen Glow Discharge, Opt. Spectroscopy 35 (1973) 11.

[46] Heidner R. F.. Husain D. and Wiesenfeld J. R.. Kinetic Investigation of Electronically Excited Oxygen Atoms $\mathrm{O}\left(2^{\prime} \mathrm{D}_{2}\right)$ by Time-Resolved Attenuation of Atomic Resonance Radiation in the Vacuum Ultra-Violet. J. Chem. Soc. Faraday Trans. II, 69 (1973) 927.

[47] Gauthier M. J. E. and Snelling D. R., Production of $\mathrm{O}_{2}\left(\mathrm{~b}^{1} \Sigma_{g}^{+}\right), v^{\prime}=0,1$ and 2 by the Reaction $\mathrm{O}\left(2^{\prime} \mathrm{D}_{2}\right)+\mathrm{O}_{2}\left(\mathrm{X}^{3} \Sigma_{\mathrm{g}}^{-}\right)$, Can. J. Chem. 52 (1974) 4007.

[48] Ogren P., Sworsky T., Hochanadel C. and Cassel J., Flash Photolysis of $\mathrm{O}_{3}$ in $\mathrm{O}_{2}$ and $\mathrm{O}_{2}-\mathrm{H}_{2}$ Mixtures. Kinetics of $\mathrm{O}_{2}\left({ }^{\prime} \Sigma_{\mathrm{g}}^{+}\right)+\mathrm{O}_{3}$ and $\mathrm{O}\left({ }^{\prime} \mathrm{D}\right)+\mathrm{H}$, Reaction, J. Phys. Chem 86 (1982) 238. 